\title{
Anabolic role of lysyl oxidase like-2 in cartilage of knee and temporomandibular joints with osteoarthritis
}

Weam Alshenibr ${ }^{1 \dagger}$, Mustafa M. Tashkandi ${ }^{1 \dagger}$, Saqer F. Alsaqer ${ }^{1}$, Yazeed Alkheriji ${ }^{1}$, Amelia Wise ${ }^{2}$, Sadanand Fulzele ${ }^{3}$, Pushkar Mehra ${ }^{4}$, Mary B. Goldring ${ }^{5,6}$, Louis C. Gerstenfeld ${ }^{2}$ and Manish V. Bais ${ }^{1 *}$

\begin{abstract}
Background: Lysyl oxidase like-2 (LOXL2) is a copper-dependent amine oxidase. Our previous studies showed that LOXL2 is elevated during mouse fracture healing. The goal of this study was to evaluate the potential of LOXL2 to act as an anabolic agent in cartilage affected by osteoarthritis (OA).

Methods: LOXL2 was visualized in tissues from human knee and hip joints and temporomandibular joints (TMJ) by immunofluorescence. The activity of LOXL2 in human articular and TMJ chondrocytes was assessed by cell-based assays, microarray analysis, and RT-qPCR, and LOXL2-mediated activation of NF-KB and extracellular signal-related kinase (ERK) signaling pathways was measured by western blotting. To examine LOXL2-induced effect in vivo, we implanted Matrigel-imbedded human chondrocytes into nude mice and exposed them to exogenous LOXL2 for 6 weeks. Finally, LOXL2-induced effects on collagen type 2 a1 (COL2A1) and phospho-SMAD2/3 were evaluated by immunofluorescence analysis.
\end{abstract}

Results: LOXL2 staining was detected in damaged regions of human TMJ, hip and knee joints affected by OA. Stimulation with transforming growth factor (TGF)- $\beta 1$ upregulated LOXL2 expression, while pro-inflammatory cytokines IL-1 $\beta$ and TNF-a downregulated LOXL2, in human chondrocytes. Viral transduction of LOXL2 in OA chondrocytes increased the mRNA levels of chondroitin sulfate proteoglycan (CSPG4), aggrecan (ACAN), sex determining region Y-box containing gene 9 (SOX9), and COL2A1 but reduced the levels of extracellular matrix (ECM)-degrading enzymes matrix metalloproteinase (MMP)1, MMP3, and MMP13. Further, forced expression of LOXL2 promoted chondrogenic lineage-specific gene expression, increased the expression of COL2A1 in the presence of TNF-a, and inhibited chondrocyte apoptosis. LOXL2 expression also inhibited IL-1 $\beta$-induced phospho-NF-kB/p65 and TGF- $\beta 1$-induced ERK1/2 phosphorylation. Matrigel constructs of human chondrocytes from the knee joint and TMJ implanted in nude mice showed anabolic responses after LOXL2 transduction, including increased expression of SOX9, ACAN, and COL2A1. Finally, immunofluorescence staining revealed co-localization of LOXL2 with SOX9 in the nuclei of cells in the implants, decreased phospho-SMAD2/3, and increased COL2A1 staining.

Conclusion: Our results suggest that although LOXL2 is upregulated in cartilage affected by OA, this may be a protective response that promotes anabolism while inhibiting specific catabolic responses in the pathophysiology of OA.

Keywords: LOXL2, Anabolic response, Cartilage, Osteoarthritis

\footnotetext{
* Correspondence: bmanish@bu.edu

${ }^{\dagger}$ Equal contributors

${ }^{1}$ Department of Molecular and Cell Biology, Boston University Henry M.

Goldman School of Dental Medicine, W-216, 700 Albany Street, Boston, MA

02118, USA

Full list of author information is available at the end of the article
} 


\section{Background}

Osteoarthritis (OA), the most common degenerative joint disease, leads to structural damage and ultimately loss of function and disability. Progressive, irreversible destruction of the joints in $\mathrm{OA}$ is driven by defective cartilage extracellular matrix (ECM) remodeling and the loss of chondrocytes due to apoptosis [1]. Knee pain and symptomatic knee OA have increased in prevalence [2], and similar manifestations of the disease process are seen in temporomandibular joint (TMJ) disorders [3]. Advances in understanding the disease pathogenesis are critical to OA prevention and treatment.

Lysyl oxidase (LOX) family members (LOX, LOXL1-4) are copper-dependent amine oxidases that function in ECM remodeling and collagen cross-linking. LOX activity is required for the formation of immature and mature pyrodinoline (PYR) cross-links in native and engineered cartilage. Hypoxia-induced LOX increases PYR crosslinks and tensile properties of the articular cartilage, knee meniscus, patellar tendon, and anterior and posterior cruciate ligaments, while exogenously applied LOX proteins are capable of enhancing collagen cross-linking and cartilage tissue functional properties [4]. Our previous studies showed that a member of the LOX family, LOXL2, is elevated during fracture healing in mice and that it promotes chondrogenesis and the formation of cartilage ECM $[5,6]$. Whether LOXL2 plays any role in the pathophysiology of $\mathrm{OA}$ and the effect on cartilage is not known.

Pro-inflammatory cytokines such as tumor necrosis factor (TNF)- $\alpha$ and interleukin (IL)- $1 \beta$ are catabolic cytokines [7] involved in chondrocyte apoptosis and matrix proteolysis; they contribute to the pathophysiology of OA [8]. Anti-cytokine agents have been evaluated for OA therapy, but with limited success $[9,10]$. Anabolic factors that have roles in chondrogenesis and articular cartilage maintenance have been used as additive factors in tissue engineering strategies and are considered as candidate structure-modifying agents for OA therapy [11]. Examples are fibroblast growth factor-18 [12] and members of the bone morphogenetic protein 2 (BMP)/ transforming growth factor $\beta 1$ (TGF- $\beta$ ) family. Differential chondrocyte responses due to aging and $\mathrm{OA}$ may account for off-target effects in joints treated with pro-anabolic agents; such effects can result in cartilage calcification, osteophyte formation, angiogenesis, and synovial fibrosis [13, 14]. Thus, alternative approaches to regulating these inflammatory cytokines could lead to improved therapies.

To better understand the role of LOXL2 in OA cartilage, we used global gene expression, immunohistochemical, and mouse xenotransplantation studies to assess the effects of LOXL2 overexpression in OA chondrocytes in vitro and in vivo. Our findings indicate that LOXL2 may act as a pro-anabolic agent in OA cartilage, providing a foundation for future work on OA therapy.

\section{Methods}

Human tissues and animal experiments

Human tissues were obtained with Institutional Review Board (IRB) approval and informed consent from all subjects. TMJ tissues were obtained from Boston University (IRB H33300). TMJ tissues were selected on the basis of clinical features such as TMJ pain and mobility and confirmed by pathological diagnostic findings as healthy or TMJ-OA, at the Department of Pathology, Boston University. The exclusion criteria included a history of any rheumatic disease or cancer. Histological slides from 16 patients (8/condition) including TMJ normal (Osteoarthritis Research Society International (OARSI) grade I) and TMJ-OA (OARSI grade V) from right and left joints were obtained. Freshly isolated cells from TMJ-OA cartilage from five patients were used for animal experiments. Histological slides of tissues from hip joints were obtained from the Department of Orthopaedic Surgery, School of Medicine, Boston University, Boston, MA, USA (IRB H-32517). Tissue sections included both uninvolved and involved regions of the femoral head based on micro computed tomography (microCT) mapping of the regions of cartilage erosion relative to bone cysts. Histological sample slides were obtained from six individuals. The OA cartilage histological tissue slides from the knee joints were obtained from Georgia Medical College, Augusta, GA, USA under IRB approval (657441-5). Tibial epiphyses from OA-affected regions (OARSI grade $\mathrm{V}$ ) and the adjacent healthy region (OARSI grade I) were collected from five patients. All mouse experiments were performed with guidance and regulations through Boston University Institutional Animal Care and Use Committee (IACUC), approval number AN-15387.

\section{Immunofluorescence of human tissue sections}

Human tissues were fixed in $4 \%$ paraformaldehyde overnight, paraffin-embedded, and sectioned for subsequent immunofluorescence by standard procedures. The tissue sections were exposed to anti-LOXL2-specific antibodies (GeneTex) or isotype control antibody; primary antibodies were detected with anti-biotin antibody combined with streptavidin-conjugated Texas red. Anti-fade reagent with 4',6-diamidino-2-phenylindole (DAPI) was added to all the samples. Sections were viewed under epifluorescence microscopy (Zeiss 710). Quantification of images was performed using Image J software (NIH), as shown in an earlier study [15]. Briefly, the region of interest was selected by drawing the margins. Parameters were set to measure area, integrated density, and mean fluorescence for stained regions, and data were obtained from several regions. Next, the same measurements were obtained 
from adjacent regions as a background control. We calculated the total corrected cellular fluorescence (TCCF):

$$
\begin{aligned}
\mathrm{TCCF} & =\text { Integrated density }-(\text { Area of selected cell } \\
& \times \text { Mean fluorescence of background readings })
\end{aligned}
$$

Data are reported as the fold-change expression compared to respective controls.

\section{RNA isolation and analysis}

Total RNA was extracted from paraffin-embedded sections of the femur, tibia, and TMJ condyle using Trizol (Qiagen) and FFPE RNA isolation kit (Qiagen), according to the manufacturer's instructions. Briefly, tissue sections were deparaffinized with Xylenes for $10 \mathrm{~min}$, washed with Xylenes then ethanol, and air-dried. Tissues were treated with proteinase $\mathrm{K}$ and RNAase inhibitor overnight and extracted with Trizol. Finally, RNA was precipitated using $10 \mu \mathrm{g}$ glycogen and isopropanol, washed with ethanol, and reconstituted in nuclease-free water. Quantitative real-time PCR (RT-qPCR) analysis was performed using TaqMan gene expression assays from Life Technologies, according to a standard protocol [16]. Taq$\mathrm{Man}^{\circ}$ Gene Expression Assay IDs for human and mouse primers were: Sex determining region Y-box containing gene 9 (SOX9) (Hs01001343_g1 and Mm00448840_m1), matrix metalloproteinase (MMP)13 (Hs00233992_m1 and Mm00439491_m1), aggrecan (ACAN) (Hs00153936_m1 and Mm00545794_m1), collagen type II $\alpha 1$ (COL2A1) (Hs00264051_m1 and Mm01309565_m1), and LOXL2 (Hs00158757_m1).

\section{Human cell cultures}

Human articular chondrocytes (HAC) from three OA patients (HAC-OA) (Cell Application Inc. from lot no. 2356, 1777, and 2881) were used. Normal HAC (HAC-N) cells were from Lonza (CC-2550). Cell lines were grown in chondrocyte growth medium $\left(\mathrm{CGM}^{\mathrm{m}}\right.$ BulletKit ${ }^{\mathrm{tw}}$, CC3216, Lonza Inc.) or in chondrocyte differentiation medium (CDM BulletKit, CC-3225, Lonza), both of which contain $5 \%$ fetal bovine serum (FBS), R3-insulin-like growth factor-1, human recombinant fibroblast growth factor-beta; insulin-transferrin-selenium (ITS), and gentamycin/amphotericin-B for in vitro studies. The chondrocyte differentiation medium also contains TGF- $\beta 3$. These supplements have been optimized for HAC $[17,18]$. The medium, with a similar composition, from Lonza and Cell Applications optimized for HAC (HAC-O and HAC) has been used in several in vitro and in vivo studies $[19,20]$ and in our experiments. Primary TMJ cells were obtained as outgrowths from explants of TMJ condylar cartilage within $24 \mathrm{~h}$ after collection as $1-\mathrm{mm}$ to $3-\mathrm{mm}$ punch biopsies, and cultured in chondrocyte growth medium with 5\% FBS (Lonza Inc.).

\section{Preparation of lentivirus and adenovirus}

Adenoviruses for transient expression of LOXL2 (AdCMV-RFP-CMV-hLOXL2-His; referred to as Ad-RFPLOXL2), and its empty vector (EV) control (Ad-RFP-EV) were custom-synthesized (ADV-214438) by Vector Biolabs. These adenovirus particles were amplified in $293 \mathrm{~T}$ cells and quantified using an adenovirus quantification kit (Cell Biolabs). The lentivirus packaging was performed using the 3-plasmid protocol [16]. Lentiviral vector for LOXL2 (CMV-LOXL2) and CMV-EV)) were purchased from Genecopoeia Inc. (EX-Y2020-Lv128 and LV128;). The expression of LOXL2 protein was evaluated by western blotting of the medium and cell layer, and enzymatic activity of purified LOXL2 was evaluated by the Amplex Red assay [21].

\section{Cell proliferation}

The CyQuant cell proliferation reagent assay (Molecular Probes), was used to measure the cell proliferation. HAC or HAC-OA cells were seeded at a density of 20,000 cells per well in 24-well plates and transduced with Adv-RFP-EV or Adv-RFP-LOXL2 in the respective group. After $24 \mathrm{~h}$, they were washed with PBS, and the plates with cell layer were stored at $-80{ }^{\circ} \mathrm{C}$. For measurements, plates were thawed at room temperature for $30 \mathrm{~min}$ and $200 \mu \mathrm{l}$ of CyQuant GR dye/cell-lysis buffer added to each well. Fluroscence measured as per manufacturer's instructions with excitation at $420 \mathrm{~nm}$ and emission detection at $535 \mathrm{~nm}$.

\section{Apoptosis assay}

HAC-N or HAC-OA were infected with the Ad-RFP-EV or ad-RFP-LOXL2 at a multiplicity of infection (MOI) of 50 in triplicate wells. The next day, cells were treated with $10 \mathrm{ng} / \mathrm{mL}$ of IL- $1 \beta, 10 \mathrm{ng} / \mathrm{mL}$ of TNF- $\alpha$, or vehicle for $24 \mathrm{~h}$ in serum-free medium. Cells were lysed using lysis buffer provided in the kit and were analyzed with a bioluminescence-based caspase-3/7 glow apoptosis assay (Promega) according to manufacturer's instructions.

\section{Molecular signaling analysis}

HAC-OA, transduced with either Ad-RFP-LOXL2 or AdRFP-EV at MOI 25, were incubated in serum-free growth medium for at least $16 \mathrm{~h}$ and then left untreated (vehicle) or treated for $10 \mathrm{~min}$ with $10 \mathrm{ng} / \mathrm{mL}$ of IL- $1 \beta$ or TGF- $\beta 1$. Proteins were extracted for western blot analysis.

\section{Western blotting}

Tissue or cell layers were extracted with SDS-PAGE sample buffer $(0.1 \mathrm{mM}$ Tris- $\mathrm{HCl}, 4 \%$ SDS, $10 \%$ glycerol, $5 \% \beta$-mercaptoethanol) and boiled for 3-5 minutes. Protein concentrations were determined using Nano Orange assay kits (Molecular Probes, Eugene, OR, USA). From tumors, approximately $20 \mu \mathrm{g}$ of protein per experimental group were then subjected to $10 \%$ SDS-PAGE and 
western blotting with primary antibodies (Cell Signaling Technology). The antibodies used were for evaluation of phospho-NF-kB-p65 (S536) and NF-kB-p65 (total), phospho-ERK1/2, total extracellular signal-related kinase (ERK) and $\beta$-actin. Anti-rabbit and anti-mouse secondary antibodies were purchased from Cell Signaling Technology. Quantification was performed using a digital densitometry system (Versadoc; BioRad, Hercules, CA, USA) and Image J software.

\section{Gene array experiments}

To evaluate the genes that were differentially regulated by LOXL2, HAC-OA from three different OA patients were cultured in chondrocyte growth medium (Lonza)

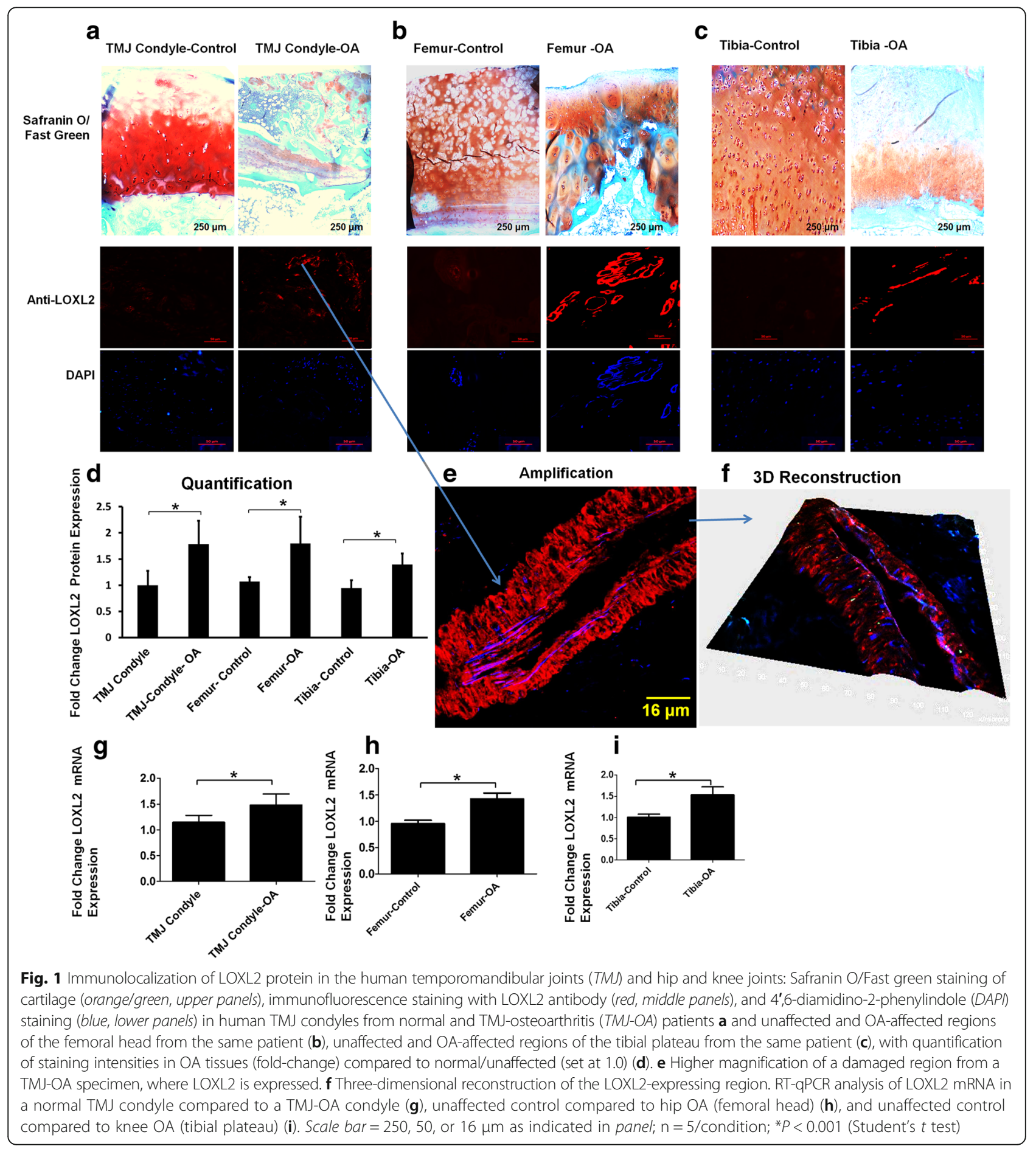


until they reached confluence and were infected with Ad-RFP-EV or Ad-RFP-LOXL2 at MOI of 25 in medium supplemented with 5\% FBS. After overnight incubation, cells were washed once with PBS and cultured overnight in the fresh serum-free medium. Cells were processed for total RNA extraction using the RNeasy kit (Qiagen). The sample integrity was verified using RNA 6000 Nano Assay RNA chips run in an Agilent 2100 Bioanalyzer (Agilent Technologies). Analysis of mRNA was performed on microarrays and by TaqMan RT-qPCR. All microarray procedures were performed at the Boston University Microarray Resource Facility, according to the protocol for the GeneChip ${ }^{\circ}$ WT Plus Kit Reagent Manual (Affymetrix,). The total RNA (100 ng) was reverse-transcribed using GeneChip ${ }^{\circ}$ WT Plus Reagent Kit (Affymetrix,). The cDNA was used as a template for in vitro transcription to antisense cRNA, which was purified using Purification Beads (Affymetrix,) and then used as a template for reverse transcription to produce single-stranded DNA in the sense orientation. Microarrays were immediately scanned using Affymetrix Gene Array Scanner 3000 7G Plus (Affymetrix). Log2 (expression) was computed across all samples and laid over a colored representation (heatmap), which was scaled so that red and blue indicated expression values $\geq 2$ standard deviations above and below, respectively, the row-wise mean (white).

\section{Gene array analysis}

Affymetrix GeneChip Human Gene 2.0 ST CEL files were normalized to produce gene-level expression values using the implementation of the Robust Multiarray Average (RMA) [22] in the Affymetrix package (version 1.36.1) [23] included in the Bioconductor software suite (version 2.12) [24] and an Entrez gene-specific probeset mapping (version 17.0.0) from the Molecular and Behavioral Neuroscience Institute (Brainarray) at the University of Michigan [25]. Array quality was assessed by computing relative log expression (RLE) and normalized unscaled standard error (NUSE) using the affyPLM Bioconductor package (version 1.34.0). Principal component analysis (PCA) was performed using the "prcomp R" function with expression values that had been normalized across all samples to a mean of zero and a standard deviation of one. Pairwise differential expression was assessed using the moderated (empirical Bayesian) $t$ test implemented in the limma package (version 3.14.4) (i.e., creating simple linear models with $\mathrm{lmFit}$, followed by empirical Bayesian adjustment with eBayes). Fold changes are indicated as $2=$ twofold higher or $-2=$ twofold lower in Ad-RFP-LOXL2- than in Ad-RFP-EVtransduced cells. Correction for multiple hypothesis testing was accomplished using the Benjamini-Hochberg false discovery rate (FDR) and represented as FDR q values. All statistical analyses were performed using the $\mathrm{R}$ environment for statistical computing (version 2.15.1).

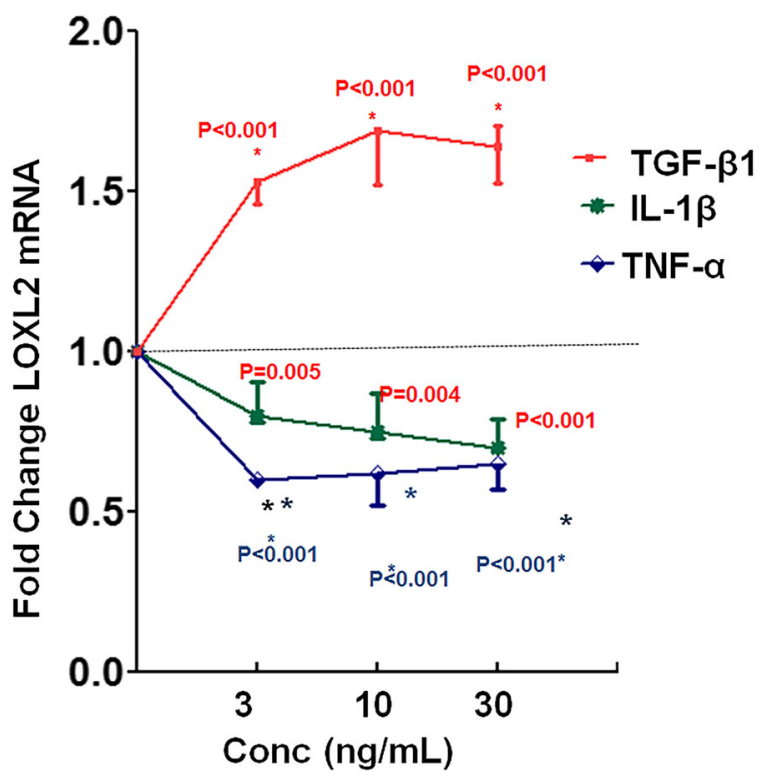

Fig. 2 Regulation of LOXL2 gene expression by osteoarthritis (OA)-related mediators: Human articular OA chondrocytes (HAC-OA) were treated with TNF- $a, I L-1 \beta$, or transforming growth factor- $\beta 1$ (TGF- $\beta 1$ ) at 10 or $30 \mathrm{ng} / \mathrm{mL}$ for $24 \mathrm{~h}$, and LOXL2 mRNA levels were assessed by RTqPCR. Data are represented as mean \pm SEM of three independent experiments with $95 \%$ confidence interval $(C I)\left({ }^{*} P<0.001\right.$; Student's $t$ test). LOXL2 gene expression was significantly upregulated by TGF- $\beta 1(P<0.001)$ and downregulated by TNF-a $(P<0.001)$ and IL-1 $\beta(P<0.001)$. 
In vivo implantation of human articular and TMJ chondrocytes in nude mice

As an alternative to various models based on human chondrocytes [26-28], we established a model using implants of primary TMJ-OA or HAC-OA chondrocytes embedded in Matrigel. For in vivo applications, freshly isolated TMJ-OA cells or frozen cells obtained from Cell Application Inc., were expanded only once to maintain their phenotype prior to preparation of implants. Freshly prepared $10^{6}$ TMJ-OA or HAC-OA chondrocytes in $50 \mu \mathrm{L}$ medium, from TMJ or knee joints of three different patients with $\mathrm{OA}$, were mixed with Matrigel at a 1:1 ratio. The total $100 \mu \mathrm{L}$ of Matrigel:chondrocyte suspension were implanted subcutaneously in the backs of nude mice (three implants/mouse) and allowed to grow for a week. These implants were treated locally with weekly injections of $30-\mu \mathrm{L}$ suspensions of Ad-RFP-LOXL2 or Ad-RFP-EV ( $\mathrm{n}=5 /$ condition), for 6 weeks. Transduction was confirmed by visualization of RFP by in vitro imaging systems (IVIS) each week. One implant from each mouse was then processed for RNA isolation, and the other two were prepared for histologic analysis and stained with Safranin $\mathrm{O} /$ Fast Green (American Mastertek Inc.).
Immunofluorescence analysis of human cartilage implants extracted from mice

Paraffin-embedded tissue sections were labeled with mouse SOX9 antibody (Abcam) or its isotype control (Vector Biolabs) detected with anti-mouse IgG conjugated to Alexa 488. To detect LOXL2 expression, the tissues were subjected to rabbit anti-LOXL2 (GeneTex), anti-RFP (Abcam), anti-phospho-SMAD2/3 (Cell Signaling Technology), anti-COL2A1 (Abcam) or its isotype control antibody and detected with anti-rabbit Alexa 488-conjugated antibody or biotin antibody followed by streptavidin-conjugated Texas red, in respective samples. Anti-fade reagent with DAPI was added to all samples. A Zeiss 710 dual scanner confocal microscope with a Plan-Apochromat objective, oil immersion lens, and a CCD detector was used to obtain confocal images. Image acquisition was performed with Zeiss Zen image analysis software (Carl Zeiss Micro Imaging). The image analysis was performed using Zeiss LSM viewer and Image J software $(\mathrm{NIH})$. Z-stack images analysis and 3-dimensional reconstruction was performed by using LOCI and the 3D viewer plug-in of Image J software. Quantification was performed using Image J software as described [15].

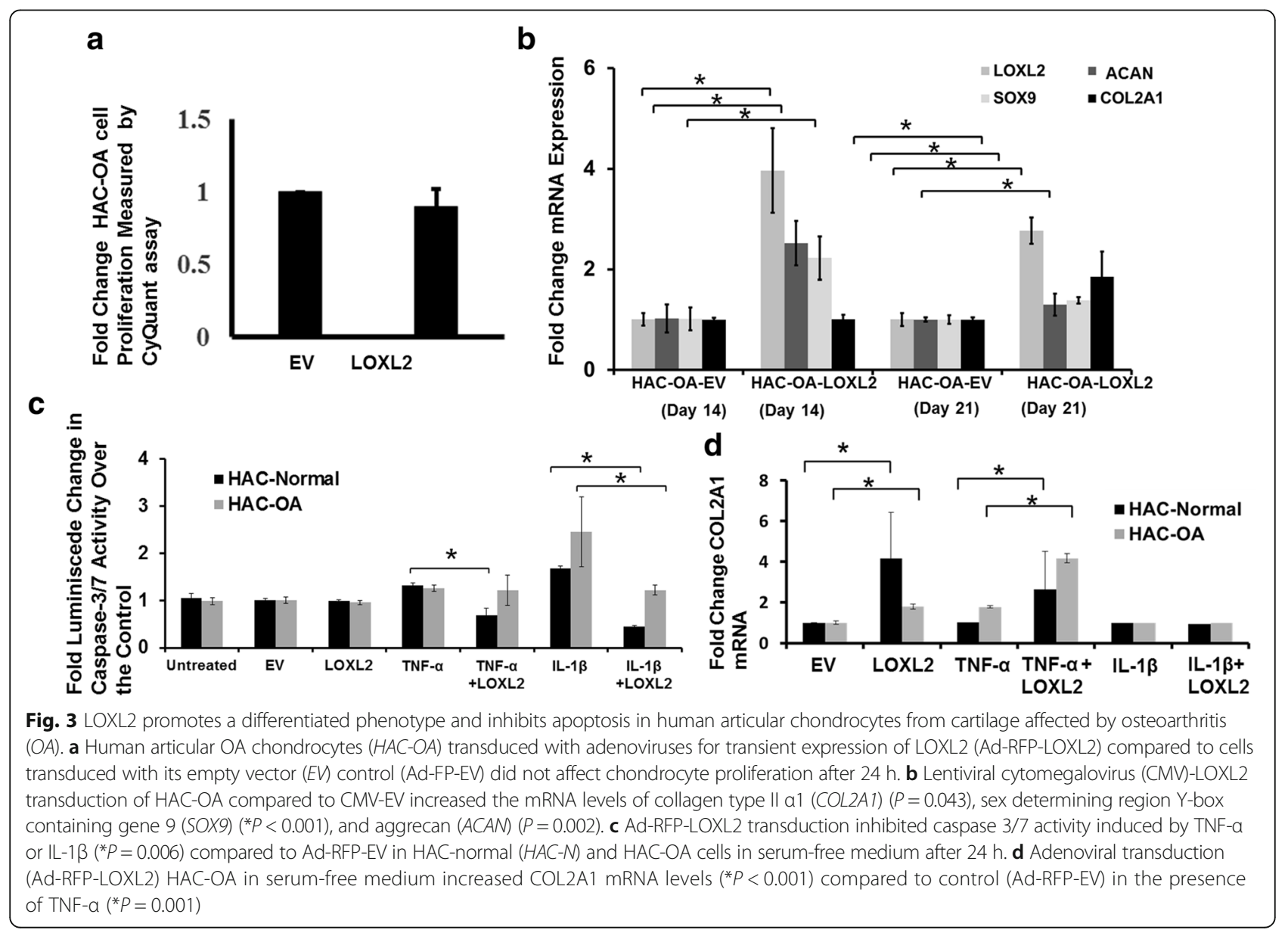




\section{Data analysis}

Data analyses were performed using two-way analysis of variance (ANOVA) with Bonferroni post-hoc analysis or Student's $t$ test (Graph Pad Prism 5 software). All experiments were performed three times each using cells derived from a different HAC-N, HAC-OA, or TMJ patient sample. Each data point is represented in the graphs as mean \pm SEM of three experiments with significance set at $P<0.05$.

\section{Results}

Immunolocalization of LOXL2 protein in human TMJ and hip and knee joints

To determine whether LOXL2 is present in OA tissues, we evaluated its localization by immunohistochemistry in healthy (OARSI, grade I) and OA tissues (OARSI grade $\mathrm{V}$ ) from multiple joints, including the TMJ condyle, the femoral head, and the tibial plateau of the knee joint. Safranin O/Fast green staining was used to identify the cartilage region (Fig. 1a). LOXL2 was detectable in damaged parts of cartilage, compared to the negligible LOXL2 in the healthy regions of tissues from all three joints (Fig. 1). Thus, LOXL2 is upregulated in damaged joints, similar to other anabolic factors such as BMP2 [29], fibroblast growth factor (FGF)18 [30], insulin-like growth factor (IGF)1, and TGF- $\beta 1$ [31], compared to cartilage not affected by OA.

\section{Regulation of LOXL2 mRNA by OA-related factors}

Whether LOXL2 expression is modulated by anabolic and catabolic factors involved in OA [7] has not been defined. Therefore, we investigated the effects of anabolic factors (TGF- $\beta 1$, IGF-1, BMP-2, and BMP-7) and catabolic factors (TNF- $\alpha$, and IL-1 $\beta$ ) on LOXL2 gene expression in chondrocytes treated for $24 \mathrm{~h}$. Compared to vehicle stimulation, LOXL2 mRNA levels in HAC-OA were induced significantly by TGF- $\beta 1$ (twofold) stimulation, whereas they were downregulated 0.5 -fold and 0.7 -fold, respectively, by TNF- $\alpha$ and IL-1 $\beta$ (Fig. 2). However, treatment with IGF-1, BMP-2, or BMP-7 produced no significant effect on LOXL2 mRNA levels in HAC-OA (not shown). These results indicate that LOXL2 gene expression can be modulated by key factors affecting OA-related processes in cartilage.

\section{LOXL2 promotes the differentiated chondrocyte phenotype and inhibits apoptosis in human chondrocytes from $O A$ cartilage \\ To evaluate if LOXL2 promotes the differentiated chondrocyte phenotype, we examined proliferation,}
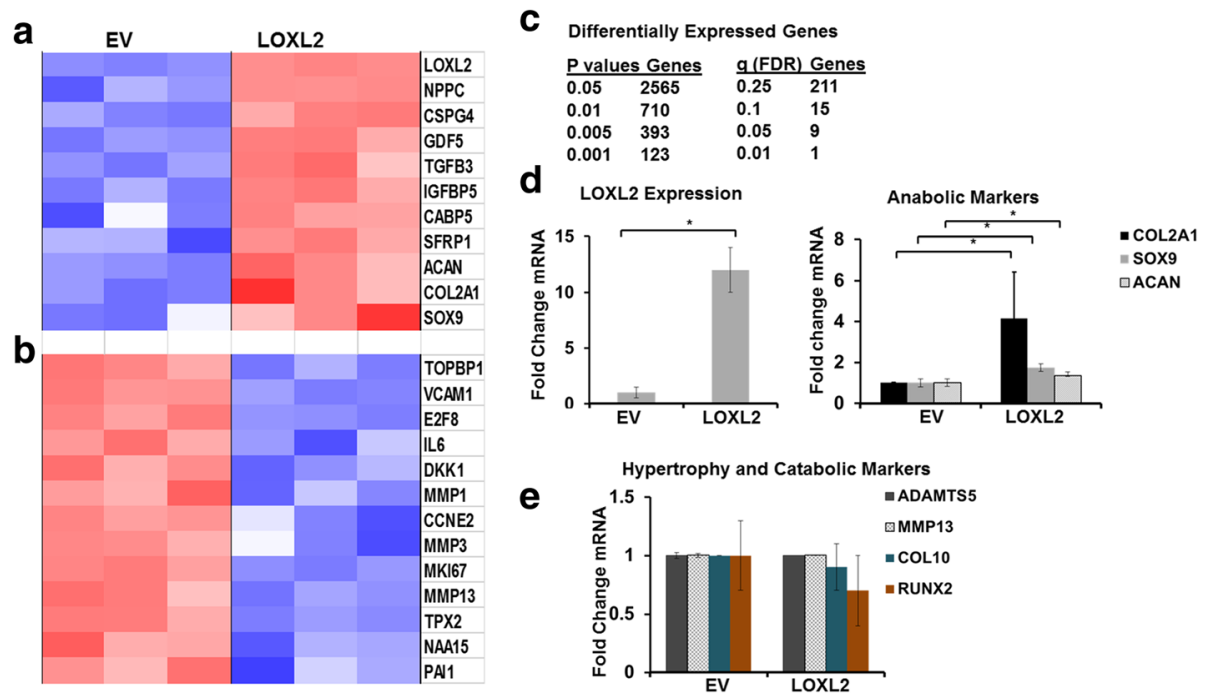

Fig. 4 LOXL2 overexpression differentially regulates genes in osteoarthritis $(\mathrm{OA})$ chondrocytes. Human articular chondrocytes from OA cartilage (HAC-OA) were transduced with adenoviruses for transient expression of LOXL2 (Ad-RFP-LOXL2) or Ad-RFP-empty vector (EV), and total RNA extracts were subjected to global gene expression analysis. LOXL2 overexpression in HAC-OA induced the upregulated gene signature (a) and the downregulated gene signature (b). c Statistical significance for differential gene expression. $\mathbf{d}$ Exogenous LOXL2 expression increased anabolic markers in HAC-OA chondrocytes, whereas genes related to chondrocyte hypertrophy and catabolic markers were not changed as validated by RT-qPCR (e) $\left({ }^{*} P<0.001\right.$; Student's $t$ test). LOXL2 transduction increased the expression of collagen type II a1 (COL2A1) $(P=0.063)$, Sex determining region Y-box containing gene 9 (SOX9) $(P=0.002)$, and aggrecan (ACAN) $(P=0.003)$. NPPC natriuretic peptide C, CSPG chondroitin sulfate proteoglycan, GDF5 growth differentiation factor 5, TGFB3 transforming growth factor B3, IGFBP3 insulin-like growth factor binding protein, CABP5 calcium binding protein 5, SFRP1 secreted frizzled-related protein 1, TOBP1 topoisomerase II binding protein 1, VCAM1 vascular cell adhesion molecule 1, E2F8 E2F transcription factor 8, DKK1 Dickkopf WNT signaling inhibitor 1, CCNE2 cyclin E2, TPX microtubule-associated homolog, NAA $\mathrm{N}$ (alpha)-acetyltransferase, FDR false discovery rate, MMP matrix metalloproteinase 
chondrocyte phenotypic markers, and TNF- $\alpha$-induced and IL-1 $\beta$-induced effects on COL2A1 mRNA and apoptosis using chondrocytes isolated from healthy cartilage (HAC-N) or OA cartilage (HAC-OA) and transduced with viral vectors. HAC-OA cells infected with Ad-RFP-LOXL2 and cultured for $24 \mathrm{~h}$ showed no significant difference in cell proliferation compared to those transduced with Ad-RFP-EV (Fig. 3a). To permit long-term expression of the transduced LOXL2 in the HAC-OA cultures for evaluation of chondrogenic differentiation, we used lentiviral vectors lenti-CMV-LOXL2 and lenti-CMV-EV (control). HAC-OA-LOXL2 cells showed increased SOX9, ACAN, and COL2A1 mRNA levels on days 14 and 21 after lenti-CMV-LOXL2 transduction and culture in chondrogenic differentiation medium compared to cells transduced with lenti-CMVEV vector (Fig. 3b). Next, we determined that LOXL2 transduction inhibits IL-1 $\beta$-induced caspase $3 / 7$ activity as a measure of apoptosis in both HAC-N and HAC-OA cells (Fig. 3c). However, LOXL2 transduction inhibited caspase $3 / 7$ activity induced by TNF- $\alpha$ in HAC-N but not in HAC-OA cells. Finally, transduction with AdRFP-LOXL2, compared to Ad-RFP-EV, increased COL2A1 mRNA levels in both healthy HAC-N and HACOA cells treated with TNF- $\alpha$ for $24 \mathrm{~h}$ (Fig. 3d). Thus, exogenous expression of LOXL2 does not affect chondrocyte proliferation, but promotes chondrogenic lineagespecific gene expression, increases COL2A1 expression in the presence of TNF- $\alpha$, and inhibits chondrocyte apoptosis.

\section{LOXL2 overexpression differentially regulates genes in OA chondrocytes}

To determine the consequences of LOXL2 overexpression on potential OA-related targets, we performed global gene expression analysis on total RNA extracted from HACOA after transduction with Ad-RFP-LOXL2 or Ad-RFPEV. LOXL2 overexpression resulted in the upregulation of genes such as natriuretic peptide C (NPPC), CSPG4, growth differentiation factor 5 (GDF5), TGFB3, insulinlike growth factor binding protein 5 (IGFBP5), calcium binding protein 5 (CABP5), secreted frizzled-related protein 1 (SFRP1), ACAN, COL2A1, and SOX9 (Fig. 4a, arranged by decreasing FDR value). Exogenous LOXL2 expression reduced the expression of genes (Fig. 4b) such as topoisomerase (DNA) II binding protein 1 (TOPBP1), vascular cell adhesion molecule 1 (VCAM1), E2F transcription factor 8 (E2F8), IL6, Dickkopf WNT signaling inhibitor 1 (DKK1), matrix metalloproteinase $(M M P)$ 1, cyclin E2 (CCNE2), MMP3, antigen identified by monoclonal antibody Ki-67 (Ki67), MMP13, microtubuleassociated homolog (TPX2), and N(alpha)-acetyltransferase (NAA)15. These expression changes were statistically significant (Fig. 4c). Validation of the global gene expression
Table 1 GSEA of selected pathways on the basis of OA-related functions from chondrocytes transduced with ADV-LOXL2 compared to empty vector (control)

\begin{tabular}{|c|c|c|c|c|}
\hline Name & Size & NES & Nom $P$ value & FDR q value \\
\hline $\begin{array}{l}\text { Reactome cell cycle } \\
\text { checkpoints }\end{array}$ & 109 & -2.478 & 0.0001 & 0.00 \\
\hline $\begin{array}{l}\text { Reactome activation of genes } \\
\text { by ATF4 }\end{array}$ & 24 & -2.234 & 0.000 & 0.00 \\
\hline $\begin{array}{l}\text { Reactome SMAD2 SMAD3 } \\
\text { SMAD4 heterotrimer } \\
\text { regulates transcription }\end{array}$ & 25 & -1.880 & 0.002 & 0.01 \\
\hline $\begin{array}{l}\text { Reactome signaling by TGF } \\
\text { Beta receptor complex }\end{array}$ & 59 & -1.748 & 0.0001 & 0.03 \\
\hline $\begin{array}{l}\text { Reactome MAPK targets } \\
\text { nuclear events mediated by } \\
\text { MAP kinases }\end{array}$ & 30 & -1.620 & 0.010 & 0.07 \\
\hline ttccgtt, MIR-191 & 29 & -1.604 & 0.012 & 0.07 \\
\hline Cell proliferation GO 0008283 & 495 & -1.578 & 0.000 & 0.08 \\
\hline Biocarta TNFR1 pathway & 29 & -1.533 & 0.033 & 0.11 \\
\hline $\begin{array}{l}\text { Negative regulation of cell } \\
\text { proliferation }\end{array}$ & 153 & -1.508 & 0.002 & 0.12 \\
\hline aagcact, MIR-520 F & 238 & -1.493 & 0.000 & 0.13 \\
\hline Regulation of angiogenesis & 26 & -1.476 & 0.061 & 0.14 \\
\hline Reactome muscle contraction & 46 & 2.023 & 0.0001 & 0.19 \\
\hline Regulation of apoptosis & 332 & -1.373 & 0.006 & 0.21 \\
\hline $\begin{array}{l}\text { Regulation of cell } \\
\text { proliferation }\end{array}$ & 298 & -1.371 & 0.010 & 0.21 \\
\hline IkB kinase NF-kB cascade & 109 & -1.36 & 0.06 & 0.23 \\
\hline Vasculature development & 55 & -1.346 & 0.072 & 0.24 \\
\hline $\begin{array}{l}\text { Reactome platelet calcium } \\
\text { homeostasis }\end{array}$ & 16 & 1.768 & 0.001 & 0.24 \\
\hline $\begin{array}{l}\text { Reactome antigen activates } b \\
\text { cell receptor leading to the } \\
\text { generation of second } \\
\text { messengers }\end{array}$ & 29 & 1.750 & 0.001 & 0.24 \\
\hline $\begin{array}{l}\text { Negative regulation of } \\
\text { developmental process }\end{array}$ & 189 & -1.335 & 0.022 & 0.25 \\
\hline
\end{tabular}

A positive NES indicates that the genes in the set are predominantly upregulated with respect to the reference group, and a negative NES indicates that the genes in the set are predominantly downregulated with respect to the reference group. GSEA gene set enrichment analysis, OA osteoarthritis, FDR false discovery rate, MAP mitogen-activated protein, TGF transforming growth factor

data by RT-qPCR analysis (Fig. 4d) showed that the key genes related to anabolic responses such as COL2A1, SOX9, and ACAN were increased after LOXL2 transduction, whereas those related to catabolic responses and chondrocyte hypertrophy such as ADAMTS5, MMP13, COL10, and RUNX2 were unchanged (Fig. 4e). Thus, our gene array analysis suggests that LOXL2 may be involved in promoting chondrogenic lineage maintenance, acting as an anabolic factor that also inhibits catabolic and angiogenic factors. 


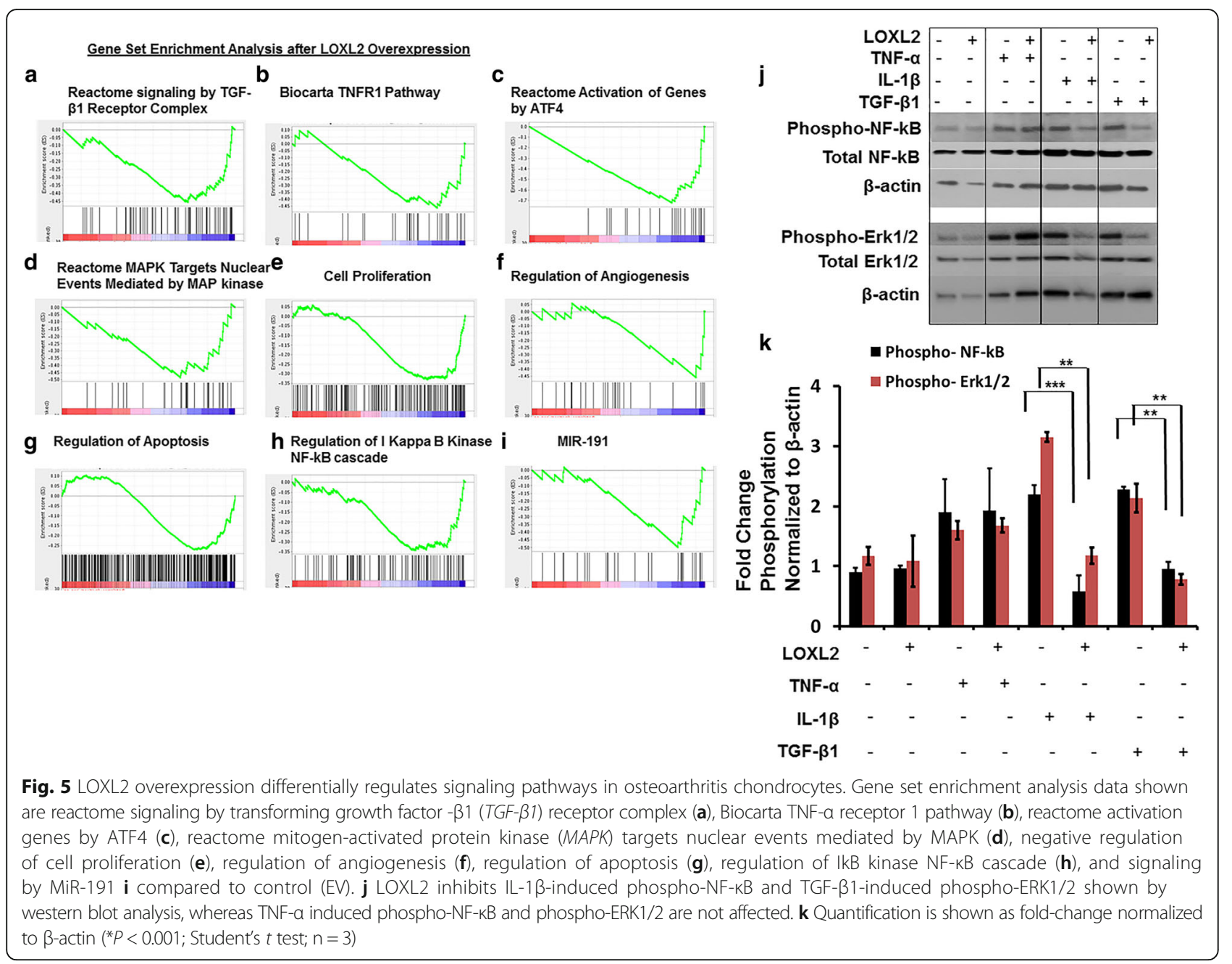

\section{LOXL2 regulates specific gene sets}

In HAC-OA transduced with Ad-RFP-LOXL2 and AdRFP-EV, $43(P$ value $<0.01)$ and $106(P$ value $<0.05)$ gene sets were enriched significantly; only 3 gene sets were enriched significantly at FDR $<25 \%(0.25)$ (Table 1 ). LOXL2 transduction compared to the EV control downregulated genes known to be involved in TGF- $\beta 1$ and TNF- $\alpha$ signaling and apoptosis (Fig. $5 \mathrm{a}-\mathrm{i}$ ); these include reactome signaling by TGF- $\beta 1$ receptor complex, Biocarta TNF- $\alpha$ receptor 1 pathway, reactome activation genes by ATF4, negative regulation of cell proliferation, regulation of angiogenesis regulation of apoptosis, reactome mitogen-activated protein (MAP) kinase nuclear events mediated by MAP kinases, regulation of $\mathrm{IkB}$ kinase NF-kB cascade, and signaling by miR-191.

\section{LOXL2 inhibits signaling pathways induced by IL-1 $\beta$ and TGF- $\beta 1$}

We next validated the inhibitory effects of LOXL2 on signaling pathways detected by gene set enrichment analysis (GSEA) (Fig. 5a-i), focusing on those involving NF- $\mathrm{KB}$ and ERK. Transduction of HAC-OA with Ad-RFP-LOXL2 inhibited IL-1 $\beta$-induced phospho-NF-kB/p65 and TGF- $\beta 1$-induced phosphoERK1/2 levels compared to cells transduced with AdRFP-EV, as shown by western blotting (Fig. $5 \mathrm{j}$ and k).

\section{LOXL2 promotes anabolic responses in implants of the human knee and TMJ-OA chondrocytes in vivo and co-expresses with SOX9}

To evaluate if LOXL2 can maintain the human cartilage phenotype long term (6 weeks) and induce specific chondrogenic differentiation in vivo, we produced a model of OA using chondrocyte/Matrigel constructs implanted subcutaneously in the backs of nude mice. We used adenoviral delivery of LOXL2 to evaluate the expression in implants of critical genes such as SOX9, ACAN, and COL2A1, which are involved in chondrogenesis. This model is an effective alternative to the human-cellbased models used previously [26-28]: it replicates the 3-dimensional cartilage environment in vivo, uses specific growth factors that preserve the differentiated 


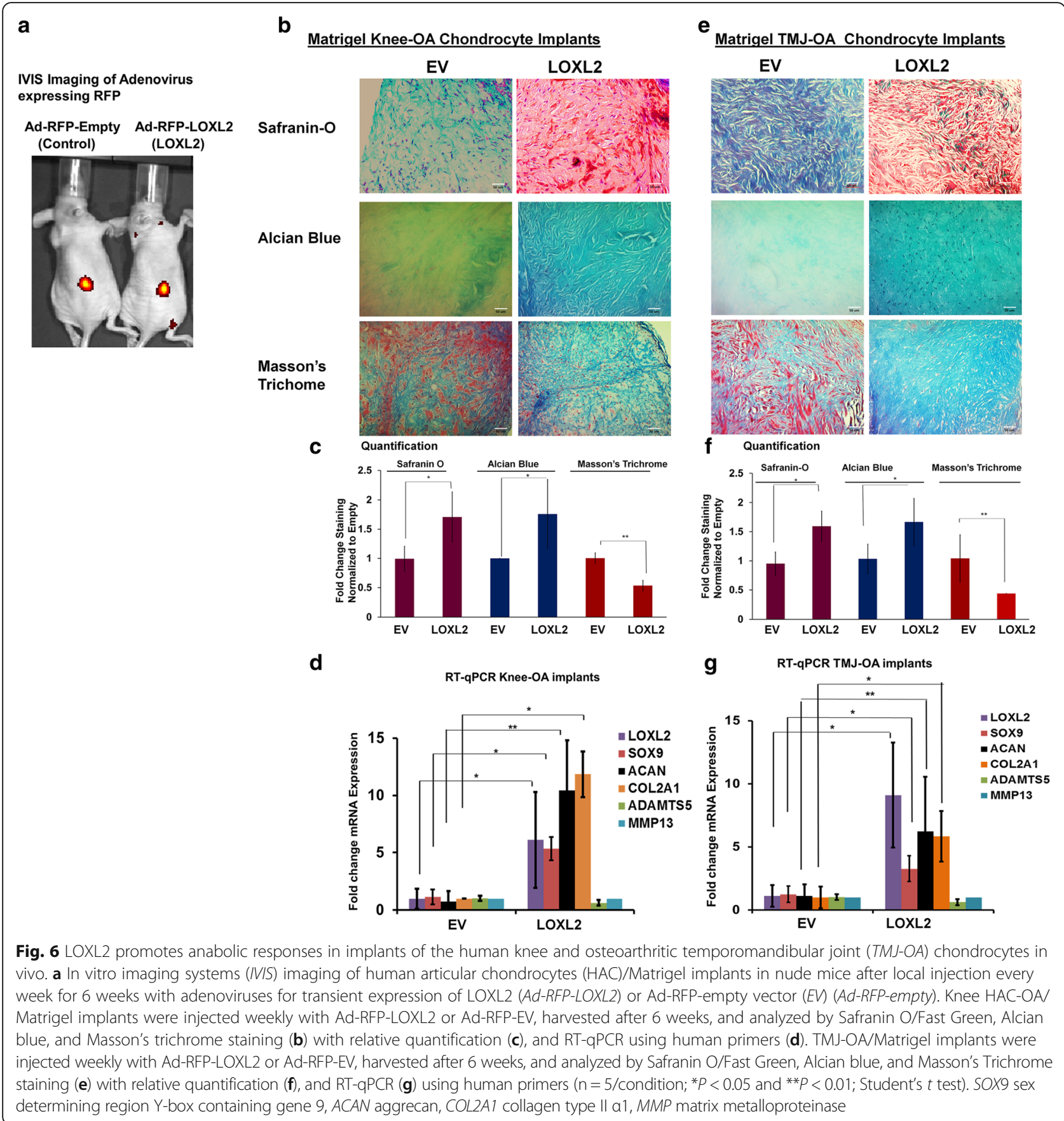

phenotype for cartilage regeneration [32], and prevents the tissues from becoming fibrotic after 6-9 weeks [33] and myogenic [34]. Weekly injections of Ad-RFP-EV or Ad-RFP-LOXL2 near the chondrocyte-Matrigel implants were performed for up to 6 weeks. IVIS imaging confirmed successful transduction by Ad-RFP-EV or Ad-RFPLOXL2 (Fig. 6a). After 6 weeks, histological sections of the retrieved implants stained with Safranin O/Fast Green and Alcian blue showed that LOXL2 transduction increased proteoglycan deposition and cartilage formation.
However, implants after transduction with Ad-RFP-EV did not show Safranin O or Alcian blue staining, consistent with loss of chondrogenic phenotype and proteoglycan deposition (Fig. 6b). Masson's trichrome staining was reduced in LOXL2-transduced implants, showing that LOXL2 promotes specific chondrogenic changes and these implants lacked mineralization and fibrosis. In contrast, implants transduced with EV appeared fibrous (Fig. 6b). Molecular analysis of implants by RT-qPCR showed that LOXL2 treatment increased the levels of 


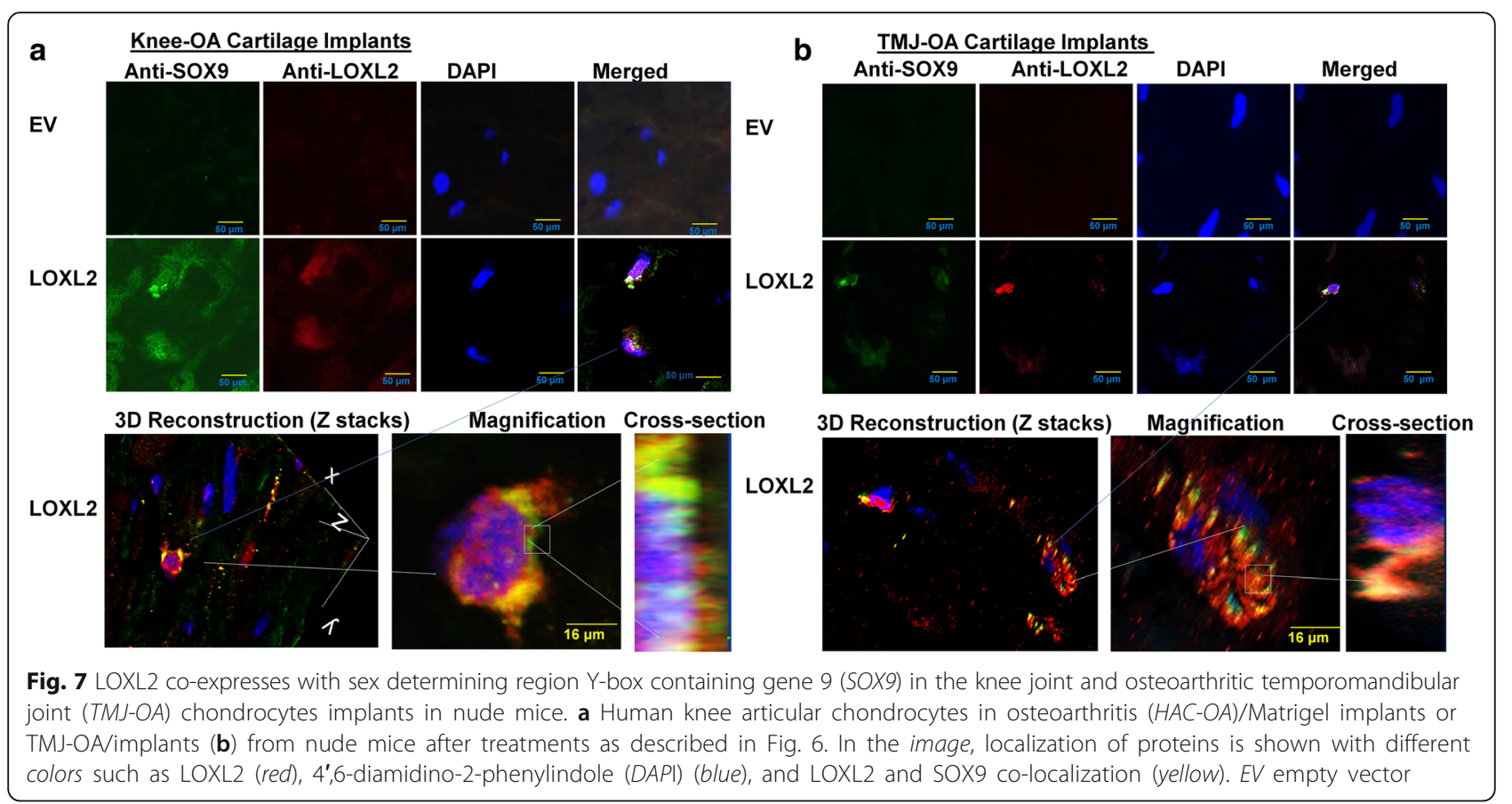

LOXL2, SOX9, COL2A1, and ACAN mRNA compared to control, whereas MMP13 and ADAMTS5 mRNA levels were not affected significantly in HAC-OA implants (Fig. 6c) and TMJ-OA implants (Fig. 6d). Finally, we evaluated LOXL2 and SOX9 by immunofluorescence staining in HAC-OA and TMJ-OA implant tissue sections. LOXL2 co-localized with nuclear SOX9 (Fig. 7). Adv-RFP-LOXL2 transduction promoted SOX9 gene expression, which was not detected in Ad-RFP-EV-transduced implants, suggesting that LOXL2 maintains the chondrogenic phenotype via SOX9. However, a co-immunoprecipitation assay did not show direct interaction of LOXL2 with SOX9 (Additional file 1: Figure S1). Finally, forced LOXL2 expression resulted in downregulation of phospho-SMAD2/ 3 and upregulation of COL2A1 compared to Ad-RFP-EVtransduced HAC-OA (Fig. 8a) and TMJ-OA implants (Fig. 8b), which showed lower expression of COL2A1. Thus, LOXL2 transduction may be critical for expression of cartilage-specific matrix genes such as COL2A1 (Fig. 8a, b). Taken together, our results show that LOXL2 induces an anabolic response in HAC-OA and TMJ-OA chondrocytes in vivo and maintains the chondrogenic phenotype, indicating its essential involvement in cartilage formation and maintenance.

\section{Discussion}

Pro-inflammatory cytokines such as TNF- $\alpha$ and IL- $1 \beta$ act as catabolic factors, promoting synovitis and altering chondrocyte differentiation, function, and viability [35-37]. We showed that LOXL2 attenuated the signaling pathways induced by TGF- $\beta 1, T N F-\alpha$, and IL- $1 \beta$. In chondrocytes, IL-1 $\beta$ and TNF- $\alpha$ activate the canonical NF- $\mathrm{kB}$ pathway, leading to catabolic and inflammatory responses [38, 39], whereas non-canonical NF-kB signaling promotes chondrocyte hypertrophy $[40,41]$. Recent studies showed that TGF- $\beta 1$ expression in subchondral bone induces OA [42], and TGF- $\beta 1$ inhibitors are chondroprotective in knee-OA and TMJ-OA in animal models [42-44]. We found that LOXL2 inhibits IL-1 $\beta$ induced phosphorylation of the $\mathrm{NF}-\mathrm{kB} / \mathrm{p} 65$ subunit, which permits translocation of the p65/p50 complex to the nucleus, and TGF- $\beta 1$-induced ERK1/2 phosphorylation, which is required for many anabolic responses in cartilage. LOX can directly interact with TGF$\beta 1$ and inhibit TGF- $\beta 1$ activity [45]. Thus, LOXL2 could interact with TGF- $\beta 1$ to negatively regulate its activity, or influence TNF- $\alpha$ and IL- $1 \beta$-induced signaling pathways. LOXL2 could also induce amine oxidation at TGF- $\beta 1$ receptor, inhibiting its activity, or attenuate downstream inflammatory signaling pathways NF-kB and ERK1/2. Indeed, LOXL2 overexpression reduces the expression of the TGF- $\beta$-responsive gene PAI1 and negatively regulates TGF- $\beta 1$-responsive gene sets and SMAD 2/3 phosphorylation. We conclude that LOXL2 could inhibit TGF- $\beta 1$ signaling, though, alternatively, LOXL2 could be a downstream target of TGF- $\beta 1$ and act through feedback inhibition of TGF- $\beta 1$-induced signaling.

LOXL2 is a naturally occurring enzyme and could have potential application in anabolic therapies. The ECM regulates diverse cellular functions, including proliferation, migration, and differentiation, and ECM remodeling is crucial for the development of normal organs. In contrast, 


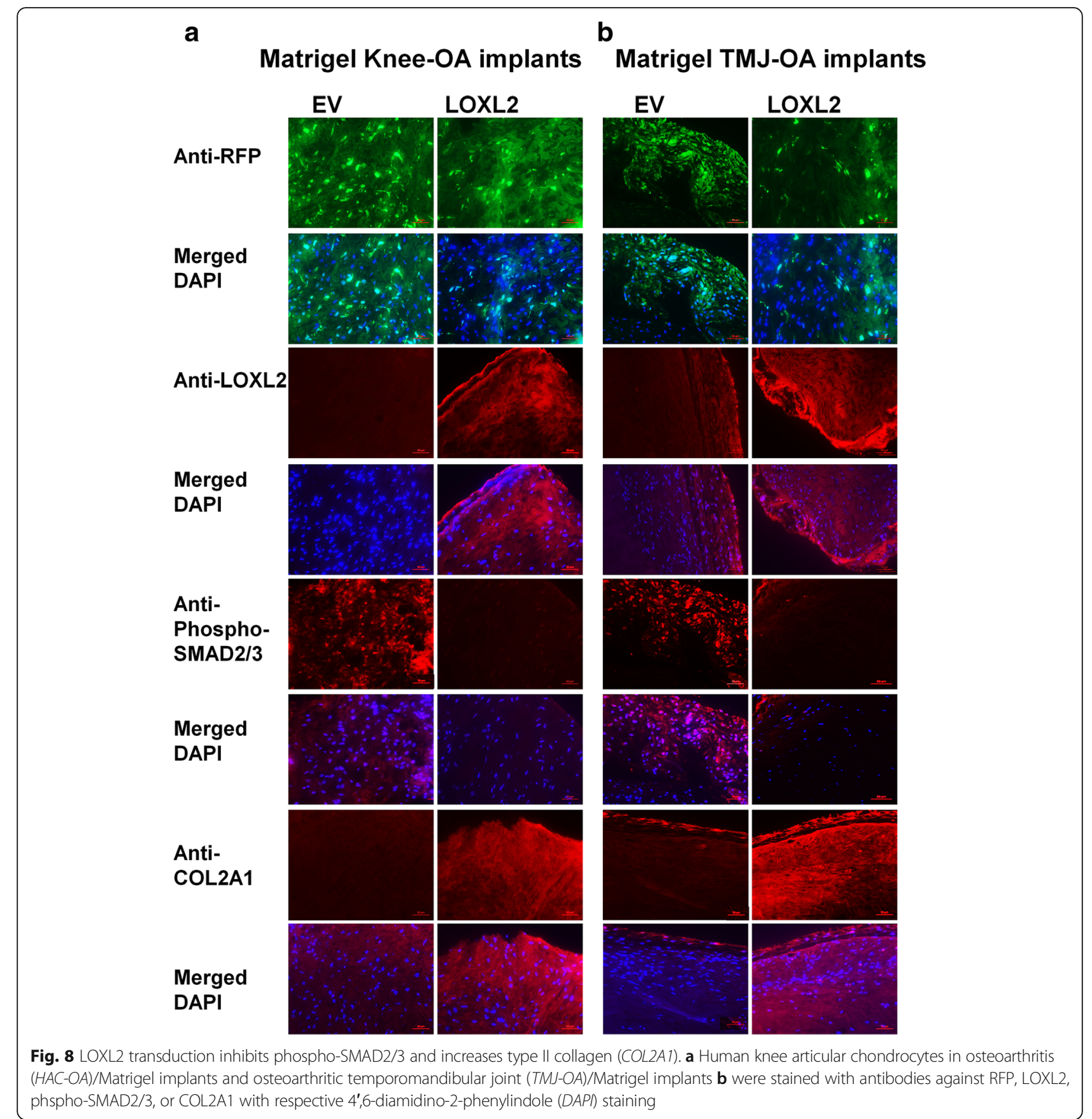

dysregulation of the ECM increases LOXL2 expression and contributes to several pathological conditions such as fibrosis and invasive cancer [46-48]. LOXL2 is increased in cancer and fibrosis as a consequence of aberrant signaling pathways and inflammatory mediators leading to remodeling of ECM [49]. Although LOXL2 is present in the damaged regions, the concentration of LOXL2 may be overcome by catabolic mediators such as IL- $1 \beta$ and TNF- $\alpha$ present in degenerative cartilage, which prevent anabolic effects induced by LOXL2 during late stages of $\mathrm{OA}$. These possibilities are under investigation in mouse models to evaluate LOXL2 as a potential therapeutic agent by the early vs. delayed administration, frequency, and dose of application. Current approaches in the development of disease-modifying OA drugs are to: (1) inhibit the ECM-degrading enzymes to prevent erosion of cartilage, (2) inhibit catabolic pro-inflammatory cytokines to protect chondrocytes against stress and inflammatory insults, and (3) develop anabolic agents to promote chondrocyte proliferation and selective differentiation [50]. Unlike other agents that affect one or two targets, our preliminary studies show 


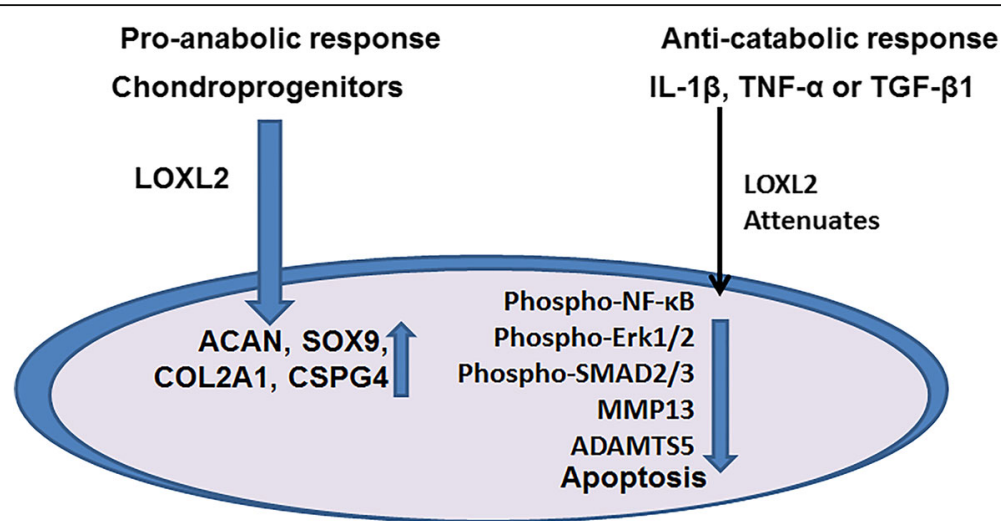

Fig. 9 Potential mechanism of LOXL2-induced anabolic effects in osteoarthritis. TGF transforming growth factor, ACAN aggrecan, COL2A1 collagen type II alpha 1, SOX9 sex determining region Y-box containing gene 9

that LOXL2 could have direct and indirect effects on all of these processes in $\mathrm{OA}$ as a potential pro-anabolic and anti-catabolic factor.

Long-term in vivo implanted human chondrocytes lose their chondrogenic phenotype and differentiation potential or become fibrous in the absence of specific stimulating anabolic factors or scaffolds [32, 33]. Our microarray data from both in vitro and in vivo experiments demonstrate that LOXL2 expression is critical for expression of chondrocyte-specific genes such as SOX9, ACAN, and COL2A1. Thus, LOXL2 could have a specific function in maintaining the chondrogenic phenotype. This is also supported by earlier studies showing that LOXL2 knockdown in chondrocytes in vitro inhibits expression of these genes and proteoglycan deposition [6].

We investigated both TMJ and knee joints affected by OA. The TMJ differs in structure compared to other joints [51], with a secondary cartilage distinct from the articular cartilage of limbs and cartilage in the cranial base. However, despite structural and functional differences in the cartilage between the knee joint and TMJ, our findings show that LOXL2 could have roles in the pathophysiology of OA in both types of joint.

Further, we show that LOXL2 co-expresses with SOX9 in the nuclei of both knee OA and TMJ OA chondrocytes in Matrigel implants in nude mice. In other cell types, LOXL2 can localize to the nucleus, perinuclear region, and cytoplasm [52, 53]. LOXL2 interacts physically and functionally with SNAIL to attenuate GSK3 $\beta$-dependent SNAIL degradation [54] and to downregulate E-cadherin expression $[55,56]$. Cytoplasmic/perinuclear localization is associated with distant metastasis of breast cancer cell line [57], while nuclear LOXL2 has a role in epithelial-tomesenchymal transition [58]. Recent findings also suggest a critical intracellular role for LOXL2 in transcriptional regulation and epigenetic changes $[52,53]$. Thus, nuclear LOXL2 could co-localize with SOX9 to cooperatively regulate gene expression. A recent study showed that
LOXL2 induces epigenetic changes during neural progenitor differentiation [53]. LOXL2 could, therefore, regulate transcription factors such as SOX9 through direct interactions or indirectly through epigenetic changes. Future investigations of LOXL2-induced epigenetic modifications through enzymatic amine oxidation and other novel mechanisms in OA chondrocytes will provide an additional foundation for understanding its role in OA pathogenesis and for the development of diseasemodifying OA drugs.

\section{Conclusions}

This is the first study to suggest a potential role for LOXL2 in the pathophysiology of OA (Fig. 9). Our hypothesis that LOXL2 acts as a specific anabolic factor in chondrocytes is supported by data showing that: (1) LOXL2 gene expression is regulated by OA-related mediators; (2) LOXL2 overexpression in chondrocytes inhibits apoptosis induced by TNF- $\alpha$ or IL-1 $\beta$; (3) LOXL2 overexpression increases SOX9, COL2A1, and ACAN mRNA levels, which are related to the differentiated chondrocyte phenotype, without increasing MMP13 or ADAMTS5; (4) LOXL2 promotes a differentiated phenotype, unlike the dual global effects seen in TGF- $\beta 1[42,44]$ and (5) LOXL2 promotes a differentiated phenotype and maintains the chondrogenic lineage in vivo. Taken together, LOXL2 promotes anabolic responses, chondrocyte differentiation, and ECM production. We are evaluating the role of LOXL2 in mouse OA models, which will provide a basic understanding of LOXL2 function for future clinical applications.

\section{Additional file}

Additional file 1: Figure S1. LOXL2 pull-down assay: HAC-OA cells were transduced with Adv-EV or Adv-LOXL2 vector for overnight. The next day, transduced cells were replenished with fresh chondrocyte growth media and cultured for $24 \mathrm{~h}$, and extracted into non-denaturing cell lysis RIPA buffer. The cell lysates were incubated with cobalt chelate NT 
beads overnight at $4{ }^{\circ} \mathrm{C}$ to pull down LOXL2. The beads were washed and eluted according to kit instructions (Pull-Down PolyHis Protein: Protein Interaction Kit Thermo Scientific, Waltham, MA, USA). Eluted samples were analyzed by western blotting on denaturing SDS-PAGE probed with an LOXL2 (Genetex) or SOX9 (Abcam) antibody, and the input (5\% aliquots) of initial extracts taken before the immunoprecipitation was analyzed on the same gels. The figure shows pull-down of LOXL2 in IP analysis; however, CO-IP with SOX9 does not show any corresponding band. (TIF $50990 \mathrm{~kb})$

\section{Abbreviations}

ACAN: Aggrecan; Ad-RFP-LOXL2: Adenoviruses for transient expression of LOXL2; BMP: Bone morphogenetic protein; CMV: Cytomegalovirus; COL2A1: Collagen type II alpha 1; CSPG: Chondroitin sulfate proteoglycan; DAPI: 4',6-Diamidino-2-phenylindole; ECM: Extracellular matrix; ERK: Extracellular signal-related kinase; EV: Empty vector; FBS: Fetal bovine serum; FDR: False discovery rate; GSEA: Gene set enrichment analysis; HAC: Human articular chondrocytes; IL: Interleukin; IRB: Institutional Review Board; IVIS: In vivo imaging systems; LOXL2: Lysyl oxidase like-2; MAP: Mitogen-activated protein; MOI: multiplicity of infection; NES: Normalized enrichment score; Nom pvalue: Nominal p-value; OA: Osteoarthritis; OARSI: Osteoarthritis Research Society International; PBS: Phosphate-buffered saline; RT-qPCR: Quantitative real-time PCR; TGF: Transforming growth factor; SOX9: Sex determining region Y-box containing gene 9; TMJ: Temporomandibular joints; TNF: Tumor necrosis factor

\section{Acknowledgements}

The authors acknowledge the funding support from NIH/NIDCR (R03DE025274) to Manish V. Bais, and the gene array analysis support provided by CTSA grant U54-TR001012A and CTSI pilot funding to Manish V. Bais. The authors also acknowledge the gift of human articular chondrocytes from three different patients from Cell Applications Inc., and IVIS spectrum imaging core for providing imaging resources. The authors acknowledge Philip Trackman for suggestions for the manuscript and resources and are thankful to Yuriy Alekseyev and Adam Gower for the gene array and its analysis.

\section{Funding}

NIH/NIDCR (R03DE025274) and CTSI pilot funding to Manish V. Bais.

\section{Availability of data and materials}

Supporting data could be obtained by reasonable request.

\section{Authors' contributions}

MB conceived and designed the study, and performed data collection, experimentation, data analysis and interpretation, and manuscript writing WA performed the experiments and analysis. MT performed the animal experiments, immunofluorescence analysis, and data analysis. SA performed the animal experiments, immunofluorescence analysis, and data analysis. YA performed the animal experiments and data analysis. AW performed the histology sections, validated by microCT, and data analysis. SF provided knee tissue sections, validated staining, and performed data analysis. PM identified subjects with TMJ-OA, performed surgical procedures, and provided samples for further analysis. LCG provided resources and manuscript editing. MBG conceived and designed the study, interpreted data, provided resources during the study, and edited the manuscript. All authors read and approved the final manuscript.

\section{Authors' information}

Not applicable.

\section{Ethical approval and consent to participate}

Animal experiments: all animal experiments and respective informed consent were obtained in accordance with relevant guidelines and regulations with Institutional Animal Care and Use Committee (IACUC) approval. All mouse experimental methods were performed with guidance and regulations and approved through Boston University Medical Center Boston, MA IACUC committee with approval number AN-15387.

Human experiments: all experiments and respective informed consent from all the subjects were obtained in accordance with relevant guidelines and regulations through IRB approval from Boston University and Georgia
Medical College, Augusta, GA. TMJ tissues were obtained through IRB approval number H33300, and femur slides were obtained through IRB approval number H-32517 from Boston University Medical Center Boston, MA. Knee joint tissues and slides were obtained from Georgia Medical College, Augusta, GA under IRB approval number 657441-5.

\section{Consent for publication}

All authors declare that they have no conflicts of interest regarding the contents of this manuscript.

\section{Competing interests}

All authors declare that they have no financial interest regarding the contents of this manuscript.

\section{Publisher's Note}

Springer Nature remains neutral with regard to jurisdictional claims in published maps and institutional affiliations.

\section{Author details}

'Department of Molecular and Cell Biology, Boston University Henry M. Goldman School of Dental Medicine, W-216, 700 Albany Street, Boston, MA 02118, USA. ${ }^{2}$ Department of Orthopaedic Surgery, School of Medicine, Boston University, Boston, MA 02118, USA. ${ }^{3}$ Department of Orthopaedic Surgery and Institute of Regenerative and Reparative Medicine, Georgia Regents University, Augusta, GA 30912, USA. ${ }^{4}$ Department of Oral and Maxillofacial Surgery, Boston University Henry M. Goldman School of Dental Medicine, 100 East Newton Street, Boston, MA 02118, USA. ${ }^{5}$ Hospital for Special Surgery Research Institute, Weill Cornell Medical College, New York, NY 10021, USA. 'Department of Cell and Developmental Biology, Weill Cornell Medical College, New York, NY 10021, USA

Received: 17 January 2017 Accepted: 17 July 2017

Published online: 02 August 2017

\section{References}

1. Zamli Z, Sharif M. Chondrocyte apoptosis: a cause or consequence of osteoarthritis? Int J Rheum Dis. 2011:14(2):159-66.

2. Nguyen US, Zhang Y, Zhu Y, Niu J, Zhang B, Felson DT. Increasing prevalence of knee pain and symptomatic knee osteoarthritis: survey and cohort data. Ann Intern Med. 2011;155(11):725-32.

3. Scrivani SJ, Keith DA, Kaban LB. Temporomandibular disorders. N Engl J Med. 2008:359(25):2693-705.

4. Makris EA, Responte DJ, Paschos NK, Hu JC, Athanasiou KA. Developing functional musculoskeletal tissues through hypoxia and lysyl oxidaseinduced collagen cross-linking. Proc Natl Acad Sci U S A. 2014;111(45): E4832-4841.

5. Ravindra PV, Tiwari AK, Ratta B, Bais MV, Chaturvedi U, Palia SK, Sharma B, Chauhan RS. Time course of Newcastle disease virus-induced apoptotic pathways. Virus Res. 2009;144(1-2):350-4.

6. Iftikhar M, Hurtado P, Bais MV, Wigner N, Stephens DN, Gerstenfeld LC, Trackman PC. Lysyl oxidase-like-2 (LOXL2) is a major isoform in chondrocytes and is critically required for differentiation. J Biol Chem. 2011; 286(2):909-18

7. Mueller MB, Tuan RS. Anabolic/catabolic balance in pathogenesis of osteoarthritis: identifying molecular targets. PM R. 2011:3(6 Suppl 1):S3-11.

8. Cho TJ, Lehmann W, Edgar C, Sadeghi C, Hou A, Einhorn TA, Gerstenfeld LC Tumor necrosis factor alpha activation of the apoptotic cascade in murine articular chondrocytes is associated with the induction of metalloproteinases and specific pro-resorptive factors. Arthritis Rheum. 2003; 48(10):2845-54

9. Calich AL, Domiciano DS, Fuller R. Osteoarthritis: can anti-cytokine therapy play a role in treatment? Clin Rheumatol. 2010;29(5):451-5.

10. Kapoor M, Martel-Pelletier J, Lajeunesse D, Pelletier JP, Fahmi H. Role of proinflammatory cytokines in the pathophysiology of osteoarthritis. Nat Rev Rheumatol. 2011;7(1):33-42.

11. Goldring MB, Berenbaum F. Emerging targets in osteoarthritis therapy. Curr Opin Pharmacol. 2015;22:51-63.

12. Lohmander LS, Hellot S, Dreher D, Krantz EF, Kruger DS, Guermazi A Eckstein F. Intraarticular sprifermin (recombinant human fibroblast growth factor 18) in knee osteoarthritis: a randomized, double-blind, placebocontrolled trial. Arthritis Rheumatol. 2014;66(7):1820-31. 
13. Blaney Davidson EN, Vitters EL, van der Kraan PM, van den Berg WB. Expression of transforming growth factor-beta (TGFbeta) and the TGFbeta signalling molecule SMAD-2P in spontaneous and instability-induced osteoarthritis: role in cartilage degradation, chondrogenesis and osteophyte formation. Ann Rheum Dis. 2006;65(11):1414-21.

14. van Beuningen $H M$, Glansbeek HL, van der Kraan PM, van den Berg WB. Differential effects of local application of BMP-2 or TGF-beta 1 on both articular cartilage composition and osteophyte formation. Osteoarthr Cartil. 1998;6(5):306-17.

15. McCloy RA, Rogers S, Caldon CE, Lorca T, Castro A, Burgess A. Partial inhibition of Cdk1 in $\mathrm{G} 2$ phase overrides the SAC and decouples mitotic events. Cell Cycle. 2014;13(9):1400-12.

16. Bais $M$, McLean J, Sebastiani $P$, Young $M$, Wigner $N$, Smith $T$, Kotton DN, Einhorn TA, Gerstenfeld LC. Transcriptional analysis of fracture healing and the induction of embryonic stem cell-related genes. PLoS One. 2009;4(5):e5393.

17. van der Kraan PM, Buma P, van Kuppevelt T, van den Berg WB. Interaction of chondrocytes, extracellular matrix and growth factors: relevance for articular cartilage tissue engineering. Osteoarthr Cartil. 2002;10(8):631-7.

18. Pei M, He F, Vunjak-Novakovic G. Synovium-derived stem cell-based chondrogenesis. Differentiation. 2008;76(10):1044-56.

19. Dua R, Comella K, Butler R, Castellanos G, Brazille B, Claude A, Agarwal A, Liao J, Ramaswamy S. Integration of stem cell to chondrocyte-derived cartilage matrix in healthy and osteoarthritic states in the presence of hydroxyapatite nanoparticles. PLoS One. 2016;11(2):e0149121.

20. Samavedi S, Diaz-Rodriguez P, Erndt-Marino JD, Hahn MS. A three-dimensional chondrocyte-macrophage coculture system to probe inflammation in experimental osteoarthritis. Tissue Eng A. 2017;23(3-4):101-14.

21. Palamakumbura AH, Trackman PC. A fluorometric assay for detection of lysyl oxidase enzyme activity in biological samples. Anal Biochem. 2002;300(2):245-51.

22. Irizarry RA, Hobbs B, Collin F, Beazer-Barclay YD, Antonellis KJ, Scherf U, Speed TP. Exploration, normalization, and summaries of high density oligonucleotide array probe level data. Biostatistics. 2003;4(2):249-64.

23. Gautier L, Cope L, Bolstad BM, Irizarry RA. affy-analysis of Affymetrix GeneChip data at the probe level. Bioinformatics. 2004;20(3):307-15.

24. Gentleman RC, Carey VJ, Bates DM, Bolstad B, Dettling M, Dudoit S, Ellis B, Gautier L, Ge Y, Gentry J, et al. Bioconductor: open software development for computational biology and bioinformatics. Genome Biol. 2004;5(10):R80

25. Dai M, Wang P, Boyd AD, Kostov G, Athey B, Jones EG, Bunney WE, Myers RM, Speed TP, Akil H, et al. Evolving gene/transcript definitions significantly alter the interpretation of GeneChip data. Nucleic Acids Res. 2005;33(20):e175.

26. Schuller GC, Tichy B, Majdisova Z, Jagersberger T, van Griensven M, Marlovits S, Redl H. An in vivo mouse model for human cartilage regeneration. J Tissue Eng Regen Med. 2008;2(4):202-9.

27. Endres M, Neumann K, Schroder SE, Vetterlein S, Morawietz L, Ringe J, Sittinger $M$, Kaps $C$. Human polymer-based cartilage grafts for the regeneration of articular cartilage defects. Tissue Cell. 2007;39(5):293-301.

28. Yahara Y, Takemori H, Okada M, Kosai A, Yamashita A, Kobayashi T, Fujita K, Itoh $Y$, Nakamura M, Fuchino H, et al. Pterosin B prevents chondrocyte hypertrophy and osteoarthritis in mice by inhibiting Sik3. Nat Commun. 2016:7:10959.

29. Fukui N, Zhu Y, Maloney WJ, Clohisy J, Sandell LJ. Stimulation of BMP-2 expression by pro-inflammatory cytokines IL-1 and TNF-alpha in normal and osteoarthritic chondrocytes. J Bone Joint Surg Am. 2003;85-A Suppl 3:59-66.

30. Snelling S, Rout R, Davidson R, Clark I, Carr A, Hulley PA, Price AJ. A gene expression study of normal and damaged cartilage in anteromedial gonarthrosis, a phenotype of osteoarthritis. Osteoarthr Cartil. 2014;22(2):334-43.

31. Karlsson C, Dehne T, Lindahl A, Brittberg M, Pruss A, Sittinger M, Ringe J. Genome-wide expression profiling reveals new candidate genes associated with osteoarthritis. Osteoarthr Cartil. 2010;18(4):581-92.

32. Vinatier C, Bouffi C, Merceron C, Gordeladze J, Brondello JM, Jorgensen C, Weiss P, Guicheux J, Noel D. Cartilage tissue engineering: towards a biomaterial-assisted mesenchymal stem cell therapy. Curr Stem Cell Res Ther. 2009;4(4):318-29.

33. Peretti GM, Randolph MA, Villa MT, Buragas MS, Yaremchuk MJ. Cell-based tissueengineered allogeneic implant for cartilage repair. Tissue Eng. 2000;6(5):567-76.

34. Cairns DM, Liu R, Sen M, Canner JP, Schindeler A, Little DG, Zeng L. Interplay of Nkx3.2, Sox9 and Pax3 regulates chondrogenic differentiation of muscle progenitor cells. PLoS One. 2012;7(7):e39642.
35. Chevalier X, Eymard F, Richette P. Biologic agents in osteoarthritis: hopes and disappointments. Nat Rev Rheumatol. 2013;9(7):400-10.

36. Husa M, Liu-Bryan R, Terkeltaub R. Shifting HIFs in osteoarthritis. Nat Med. 2010;16(6):641-4.

37. Liu-Bryan R, Terkeltaub R. Emerging regulators of the inflammatory process in osteoarthritis. Nat Rev Rheumatol. 2015;11(1):35-44.

38. Marcu KB, Otero M, Olivotto E, Borzi RM, Goldring MB. NF-kappaB signaling: multiple angles to target OA. Curr Drug Targets. 2010;11(5):599-613.

39. Olivotto E, Otero M, Marcu KB, Goldring MB. Pathophysiology of osteoarthritis: canonical NF-kappaB/IKKbeta-dependent and kinase-independent effects of IKKalpha in cartilage degradation and chondrocyte differentiation. RMD Open. 2015;1 Suppl 1:e000061.

40. Olivotto E, Otero M, Astolfi A, Platano D, Facchini A, Pagani S, Flamigni F, Facchini A, Goldring MB, Borzi RM, et al. IKKalpha/CHUK regulates extracellular matrix remodeling independent of its kinase activity to facilitate articular chondrocyte differentiation. PLoS One. 2013;8(9):e73024

41. Rigoglou S, Papavassiliou AG. The NF-kappaB signalling pathway in osteoarthritis. Int J Biochem Cell Biol. 2013;45(11):2580-4.

42. Zhen G, Wen C, Jia X, Li Y, Crane JL, Mears SC, Askin FB, Frassica FJ, Chang W, Yao J, et al. Inhibition of TGF-beta signaling in mesenchymal stem cells of subchondral bone attenuates osteoarthritis. Nat Med. 2013;19(6):704-12.

43. Long E, Motwani R, Reece D, Pettit N, Hepworth J, Wong P, Reynolds P, Seegmiller R. The role of TGF-ss1 in osteoarthritis of the temporomandibular joint in two genetic mouse models. Arch Oral Biol. 2016;67:68-73.

44. Blaney Davidson EN, van der Kraan PM, van den Berg WB. TGF-beta and osteoarthritis. Osteoarthr Cartil. 2007:15(6):597-604.

45. Atsawasuwan P, Mochida Y, Katafuchi M, Kaku M, Fong KS, Csiszar K, Yamauchi M. Lysyl oxidase binds transforming growth factor-beta and regulates its signaling via amine oxidase activity. J Biol Chem. 2008; 283(49):34229-40.

46. Bonnans C, Chou J, Werb Z. Remodelling the extracellular matrix in development and disease. Nat Rev Mol Cell Biol. 2014;15(12):786-801.

47. Barker HE, Cox TR, Erler JT. The rationale for targeting the LOX family in cancer. Nat Rev Cancer. 2012;12(8):540-52.

48. Akiri G, Sabo E, Dafni H, Vadasz Z, Kartvelishvily Y, Gan N, Kessler O, Cohen T, Resnick M, Neeman M, et al. Lysyl oxidase-related protein-1 promotes tumor fibrosis and tumor progression in vivo. Cancer Res. 2003:63(7):1657-66.

49. Torres S, Garcia-Palmero I, Herrera M, Bartolome RA, Pena C, FernandezAcenero MJ, Padilla G, Pelaez-Garcia A, Lopez-Lucendo M, Rodriguez-Merlo R, et al. LOXL2 is highly expressed in cancer-associated fibroblasts and associates to poor colon cancer survival. Clin Cancer Res. 2015;21(21):4892-902.

50. Johnson K, Zhu S, Tremblay MS, Payette JN, Wang J, Bouchez LC, Meeusen S, Althage A, Cho CY, Wu X, et al. A stem cell-based approach to cartilage repair. Science. 2012;336(6082):717-21.

51. Hinton RJ. Genes that regulate morphogenesis and growth of the temporomandibular joint: a review. Dev Dyn. 2014;243(7):864-74.

52. Iturbide A, Garcia de Herreros A, Peiro S. A new role for LOX and LOXL2 proteins in transcription regulation. FEBS J. 2015;282(9):1768-73.

53. Iturbide A, Pascual-Reguant L, Fargas L, Cebria JP, Alsina B, Garcia de Herreros A, Peiro S. LOXL2 oxidizes methylated TAF10 and controls TFIIDdependent genes during neural progenitor differentiation. Mol Cell. 2015; 58(5):755-66.

54. Peinado H, Portillo F, Cano A. Switching on-off Snail: LOXL2 versus GSK3beta. Cell Cycle. 2005:4(12):1749-52.

55. Peinado H, Del Carmen Iglesias-de la Cruz M, Olmeda D, Csiszar K, Fong KS, Vega S, Nieto MA, Cano A, Portillo F. A molecular role for lysyl oxidase-like 2 enzyme in snail regulation and tumor progression. EMBO J. 2005;24(19): 3446-58.

56. Canesin G, Cuevas EP, Santos V, Lopez-Menendez C, Moreno-Bueno G, Huang Y, Csiszar K, Portillo F, Peinado H, Lyden D, et al. Lysyl oxidase-like 2 (LOXL2) and E47 EMT factor: novel partners in E-cadherin repression and early metastasis colonization. Oncogene. 2015;34(8):951-64.

57. Moreno-Bueno G, Salvador F, Martin A, Floristan A, Cuevas EP, Santos V, Montes A, Morales S, Castilla MA, Rojo-Sebastian A, et al. Lysyl oxidase-like 2 (LOXL2), a new regulator of cell polarity required for metastatic dissemination of basal-like breast carcinomas. EMBO Mol Med. 2011;3(9): 528-44.

58. Moon HJ, Finney J, Xu L, Moore D, Welch DR, Mure M. MCF-7 cells expressing nuclear associated lysyl oxidase-like 2 (LOXL2) exhibit an epithelial-to-mesenchymal transition (EMT) phenotype and are highly invasive in vitro. J Biol Chem. 2013;288(42):30000-8. 